\title{
Testicular Cancer cM0 TNM Finding v8
}

National Cancer Institute

\section{Source}

National Cancer Institute. Testicular Cancer CMO TNM Finding v8. NCI Thesaurus. Code C140189.

Testicular cancer without evidence of distant metastasis. (from AJCC 8th Ed.) 